\title{
Prescription pattern and prevalence of potentially inappropriate medications among elderly patients in a Nigerian rural tertiary hospital
}

This article was published in the following Dove Press journal:

Therapeutics and Clinical Risk Management

12 March 2013

Number of times this article has been viewed

Joseph O Fadare'

Segun Matthew Agboola ${ }^{2}$ Olumide Augustine Opeke ${ }^{3}$

Rachel A Alabi ${ }^{4}$

'Department of Medical Pharmacology and Therapeutics, Obafemi

Awolowo University, Ile-Ife, Nigeria;

${ }^{2}$ Department of Family Medicine,

${ }^{3}$ Department of Internal Medicine,

${ }^{4}$ Pharmacy Department, Federal

Medical Centre, Ido-Ekiti, Nigeria
Correspondence: Joseph O Fadare Department of Medical Pharmacology and Therapeutics, Obafemi Awolowo University, lle-lfe, Nigeria

Tel +2348I3804 8I27

Email jofadare@gmail.com
Introduction: Polypharmacy and inappropriate prescriptions are prominent prescribing issues with elderly patients. Beers criteria and other guidelines have been developed to assist in the reduction of potentially inappropriate medications prescribed to elderly patients. The objectives of this study were to assess the prescribing pattern for elderly Nigerian outpatients and estimate the prevalence of potentially inappropriate medications among them using the Beers criteria.

Methodology: This was a prospective cross-sectional study of elderly patients (65 years and above) who were attending the general outpatients clinic of a rural Nigerian hospital. For the drug utilization aspect of the study, drug-use indicators were assessed using established World Health Organization guidelines, while the Beers criteria was used to screen for potentially inappropriate medications.

Result: The medical records of 220 patients aged 65 years and above were utilized for the study. A total of 837 drugs were prescribed for the patients, giving an average of $3.8 \pm 1.3$ drugs per person. Antihypertensive drugs accounted for $30.6 \%$ of the prescriptions, followed by multivitamins/food supplements (11.5\%) and analgesics (10.8\%). A review of the prescribed medications using the 2012 Updated Beers Criteria by the American Geriatric Society identified 56 patients with at least one potentially inappropriate medication prescribed giving a rate of $25.5 \%$. The drug groups identified were nonsteroidal anti-inflammatory drugs, antihistamines, and amitriptyline.

Conclusion: Polypharmacy and prescription of potentially inappropriate medications are major therapeutic issues in Nigeria. There is a need for prescriber training and retraining with emphasis on the geriatric population.

Keywords: drug utilization pattern, elderly patients, rational use of medicines, adverse drug reactions, Beers criteria

\section{Introduction}

The elderly account for a significant part of the population in many countries of the world, with over $60 \%$ of the world's elderly found in developing countries. ${ }^{1}$ Drug use in the elderly is fraught with many problems because of the following factors: the physiologic changes of aging and potential drug-drug and drug-disease interactions. ${ }^{2}$ Polypharmacy and the inappropriate use of medicines in the elderly have been identified as major types of nonrational prescribing in the elderly leading to higher prevalence of adverse drug reactions among them. ${ }^{3-5}$ These factors have also been shown to be responsible for a disproportionately high rate of adverse drug reactions among elderly patients and its associated increased healthcare costs. ${ }^{6,7}$ Prescription of potentially inappropriate medications (PIMs) has been found to be a common cause of morbidity and mortality 
among the elderly and has necessitated the creation of criteria for the safe use of medicines among the elderly, namely the Beers criteria, which was initially released in 1997 and updated in 2002 and 2012..$^{8-10}$ The Beers criteria are based on a consensus of experts from different disciplines like geriatrics, clinical pharmacology, and psychopharmacology who used an adopted Delphi method. The Beers criteria consist of medications to be avoided in the elderly irrespective of the patient's diagnosis, and those that should be avoided when taking a particular diagnosis into account. Inappropriate prescriptions (IPs), according to Beers criteria, could also be classified as high or low severity depending on the perceived severity of the expected adverse drug reaction. ${ }^{8}$ Several studies in Europe have recorded the prevalence of IPs to be in the range of 9.8\%-25.8\%.$^{11-15}$ Data from studies in USA showed rates of between $21.3 \%-37 \%$ among outpatients, while nursing home residents have rates of IP up to $40 \% .{ }^{16-18}$ From India, Lebanon, and Taiwan, the rates of IP were $23.6 \%, 22.4 \%$, and $19.5 \%$ respectively. ${ }^{19-21}$ The Beers criteria are not without their deficiencies, especially as they relate to prescriptions in many European countries, and this has led to the development of newer tools such as the Screening Tool of Older Person's Prescriptions (STOPP) and Screening Tool to Alert Doctors to Right Treatment (START). ${ }^{13,22}$ The Beers criteria could be used as a template upon which countries can develop their own screening tools, as in the case of Taiwan. ${ }^{23}$

Several studies in Nigeria have investigated the general prescription pattern among patients attending the general outpatients' department, but, to the knowledge of the authors, only Amanor-Boadu ${ }^{26}$ dealt with geriatric drug utilization with emphasis on patients prepared for general anesthesia. ${ }^{24-26}$ More importantly, we have not found any study on prescription of PIMs among the elderly in Nigeria, hence the need for this study.

The main objective of this study was to investigate the prescribing pattern for geriatric patients attending the general outpatient department of a rural tertiary hospital in southwest Nigeria. In addition, the study investigated the prevalence of PIMs among this cohort using the Beers criteria.

\section{Methods}

\section{Study setting}

The study was conducted at the general outpatients' department of the Federal Medical Centre, Ido-Ekiti, a tertiary health care facility in southwest Nigeria. The department is usually the first point of contact for patients attending the hospital and it is manned by consultants and resident doctors in family medicine/general practice.

\section{Ethical considerations}

The study received ethical approval from the hospital's research ethics committee prior to commencement of the study.

\section{Methods}

The study was prospective and cross sectional, involving patients aged 65 years and above. All patients that met this criterion and gave consent were recruited over a 3-month period (April-June 2011). The medical records (case files) of the patients were retrieved from the consulting rooms at the end of each working day and the information obtained from them was transferred into a prepared data sheet. Information retrieved from the files included the age and sex, medical conditions (diagnosis) for which the patient was receiving treatment, and the prescribed drugs and their dosages. For the drug utilization aspect of the study, drug use indicators were assessed using some WHO guidelines on investigation of drug use in health care facilities: ${ }^{25}$ average number of drugs per prescription, percentage of drugs prescribed by generic names, and percentage of encounters with antibiotics. The pattern of prescription of analgesics and sedatives was also assessed. For the inappropriate prescribing section of the study, a full updated American Geriatric Society version (2012) of the Beers criteria ${ }^{10}$ was downloaded and printed out. The prescribed medications were then assessed using these criteria to determine their appropriateness.

\section{Analysis}

Data generated from the case notes were recorded on a spreadsheet and analyzed using SPSS v 16 (IBM Corporation, Armonk, NY, USA). Results are expressed as means, frequencies, and percentages. Chi square test and ANOVA were used to compare the means of different groups among the study population. Values of $P<0.05$ were considered as significant. The list of PIMs found among the patients were compiled and calculated as percentages.

\section{Results}

The medical records of 220 patients aged 65 years and above were utilized for the study. The mean age was $72.8 \pm 7.2$ years and female patients represented $58.2 \%$ of the study population. Distribution of the patients according to age groups revealed that $61.8 \%$ of the patients fell into the $65-74$ years bracket while $30.5 \%$ and $7.7 \%$ were in the 74-85 years and above 85 years categories. One hundred and twenty elderly patients $(54.5 \%)$ visited the hospital on 
account of systemic hypertension with 71 (59.2\%) of them having only hypertension while $18.3 \%$ had hypertension with diabetes mellitus and the remaining $22.5 \%$ had systemic hypertension with other co-morbidities. Other medical conditions for which the patients were seen in the hospital are diabetes mellitus alone (6.4\%), malaria (6.4\%), and osteoarthritis (5.5\%) (Table 1).

A total of 837 drugs were prescribed for the patients, giving an average of $3.8 \pm 1.3$ drugs per person. Sixty-five (29.5\%) patients had five drugs or more prescribed for them while 114 (51.8\%) had 3-4 drugs (see Figure 1). The mean number of drugs prescribed for patients within the age group of 65-74 years was 3.76, for those aged 75-84 years it was 4.04, and for those 85 years and above it was 3.26 . The difference between the three groups was statistically significant $(P=0.004)$. The mean number of drugs prescribed was also compared between the male and female patients with the former group having $3.63 \pm 1.23$ drugs prescribed while the latter group had $3.93 \pm 1.35$, a difference with no statistical significance $(P=0.094)$. Antihypertensive drugs accounted for $30.6 \%$ of the prescriptions, followed by multivitamins and food supplements (11.5\%). Analgesics accounted for $10.8 \%$ while antibiotics, oral hypoglycemic agents, and sedatives were prescribed in $7.8 \%, 7.5 \%$, and $2.6 \%$, respectively. The breakdown of prescribed antihypertensives showed calcium channel blockers as the most prescribed ( $10.5 \%$ of all prescriptions), followed by the

Table I Diagnosis of patients

\begin{tabular}{lll}
\hline Diagnosis & Frequency (n) & Percentage \\
\hline Hypertension (alone) & 71 & 32.3 \\
Hypertension + DM & 22 & 10 \\
Hypertension + other comorbidity & 27 & 12.3 \\
DM (alone) & 14 & 6.4 \\
Malaria & 14 & 6.4 \\
Osteoarthritis & 12 & 5.5 \\
COPD & 8 & 3.6 \\
Peptic ulcer disease & 7 & 3.2 \\
Respiratory tract infection & 7 & 3.2 \\
Parkinson's disease & 4 & 1.8 \\
Urinary tract infection & 4 & 1.8 \\
Congestive cardiac failure & 3 & 1.3 \\
Gastroenteritis & 3 & 1.3 \\
Peripheral neuropathy & 3 & 1.3 \\
Myalgia & 3 & 1.3 \\
Essential tremor & 2 & 0.9 \\
Meniere's disease & 2 & 0.9 \\
Lumbago & 2 & 0.9 \\
Others & 12 & 5.5 \\
Total & 220 & 100 \\
\hline Abbreviations COPD, hronc &
\end{tabular}

Abbreviations: COPD, chronic obstructive pulmonary disease; DM, diabetes mellitus.

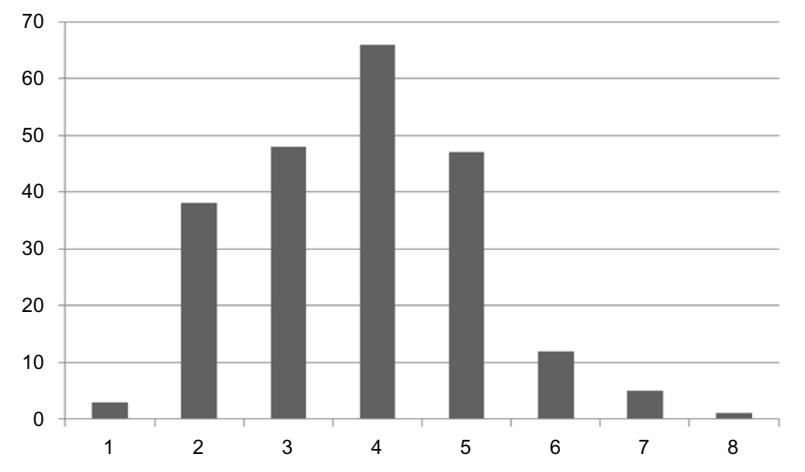

Figure I Number of medications per prescription.

fixed-dose combination drug amiloride/hydrochlorothiazide (10.4\%) and ACE inhibitors (7.4\%). The beta-blocker Atenolol was prescribed in only five $(0.6 \%)$ patients while six of them had $\alpha$-methyldopa. Regarding the number of antihypertensives prescribed per patient, $26(11.8 \%)$ had only one, $74(33.6 \%)$ had two, 26 (11.8\%) had three, and only one patient had four antihypertensives prescribed. The most common combination found among patients with two drugs was nifedipine/amiloride/hydrochlorothiazide combination (35\%), followed by lisinopril/amiloride/hydrochlorothiazide combination (20.2\%). Acetylsalicylic acid (75 mg) accounted for $8.6 \%$ of the total drugs prescribed, with $32.7 \%$ of the patients having it prescribed for them. Paracetamol was the most prescribed analgesic with $60 \%$, followed by nonsteroidal anti-inflammatory drugs (NSAIDs) $(22.2 \%)$ and the opiate analgesic tramadol (17.8\%). Among the 36 patients that had oral hypoglycemic agents, metformin and glibenclamide were prescribed as combination therapy in $75 \%$ of the patients. Forty-seven patients had an antibiotic prescribed, with 31 (66\%), 14 (29.8\%), and 2 (4.2\%) having one, two, and three antibiotic drugs, respectively. Artemisinin-based anti-malaria drugs accounted for $6.5 \%$ of the total number of drugs. The anxiolytic/sedative drug bromazepam constituted $77 \%$ of all drugs prescribed in this category with the long-acting benzodiazepine, diazepam in the remaining $23 \%$. Other prescribed drugs include amitriptyline, benzhexol, cinnarizine, prochlorperazine, chlorpheniramine, omeprazole, and diphenhydramine-containing cough mixtures (Table 2).

With regard to prescribing by generic names, only $43.2 \%$ of the prescribed drugs were by generic names.

The review of the prescribed medications using the 2012 Updated Beers Criteria by the American Geriatric Society identified 56 patients with at least one PIM prescribed giving a rate of $25.5 \%$. A total of 66 PIMs were prescribed in all with 14 responsible medications identified. NSAIDs were the 
Table 2 Frequency of prescribed drugs

\begin{tabular}{ll}
\hline Drug group & Percentage \\
\hline Antihypertensives & 30.6 \\
Multivitamins/food supplements & 11.5 \\
Analgesics & 10.8 \\
Acetylsalicylic acid & 8.6 \\
Antimicrobials & 7.8 \\
Oral hypoglycemic agents & 7.5 \\
Anti-malaria drugs & 6.5 \\
Anti-ulcer drugs & 3.7 \\
Sedatives & 2.6 \\
Cough syrup & 2.2 \\
Drugs for heart failure & 1.7 \\
Others & 6.5 \\
\hline
\end{tabular}

Note: alncludes simvastatin, cinnarizine, chlorpheniramine, sinemet/carbidopa, benhexol, orphenadrine, bisolvon, albendazole, salbutamol, aminophylline, prednisolone, and pregabalin.

identified PIMs in 20 cases, followed by antihistamines (19), while Amitriptyline and $\alpha$-Methyldopa were implicated in ten and six cases, respectively. Nitrofurantoin, diazepam, doxazosin, benzhexol, ergotamine, and orphenadrine were the remaining identified PIMs (Table 3).

\section{Discussion}

The preponderance of female patients $(58.2 \%)$ in this study is similar to results from similar studies in USA and Europe. ${ }^{17,27}$ In many countries, females tend to have a higher life expectancy than males and the figures from Nigeria confirm this numerical advantage of elderly (above 65 years) women. ${ }^{28,29}$ This could explain, to a certain degree, the overall female preponderance seen in our study. However, the situation is different in a few countries and this is clearly shown by some Indian studies among the elderly, where a predominantly male population of $60.6 \%$ and $60 \%$, was found. ${ }^{16,30}$ Economic factors may also play a role in the health seeking pattern of this group of patients.

Table 3 Frequency of the prescription of PIMs

\begin{tabular}{lll}
\hline PIM & Frequency $(\mathbf{n})$ & Percentage \\
\hline NSAIDs & 20 & 30.3 \\
Antihistamines & 19 & 28.8 \\
Amitriptyline & 10 & 15.2 \\
Q-Methyldopa & 6 & 9.1 \\
Diazepam & 3 & 4.5 \\
Nitrofurantoin & 3 & 4.5 \\
Doxazosin & 2 & 3.0 \\
Benzhexol & 1 & 1.5 \\
Orphenadrine & 1 & 1.5 \\
Ergotamine & 1 & 1.5 \\
Total & 66 & 100 \\
\hline
\end{tabular}

Abbreviations: NSAIDs, nonsteroidal anti-inflammatory drugs; PIM, potentially inappropriate medication.
The mean age found in this study $(72.8 \pm 7.2$ years $)$ is similar to that found in other studies..$^{20,32}$ The main cause of morbidity found in our study was from cardiovascular conditions with $54.5 \%$ of the patients having hypertension. Similar studies carried out in different centers in India also revealed hypertension as the major cause of morbidity affecting $45 \%$ and $40.3 \%$ of the participants, respectively. ${ }^{33,34}$ This shows that our finding is in keeping with the trend of increasing morbidity from noncommunicable diseases in developing countries.

The average number of drugs prescribed in this study $(3.8 \pm 1.3)$ is in the same range as results from other general prescription studies done in Nigeria. ${ }^{24,25}$ Studies carried out among geriatric patients in Turkey, USA, India, Brazil, and Poland found an average of 2.9, 8.1, 4.3, 3.2, and 6.6 drugs per prescription. ${ }^{11,17,34-36}$ The prescription with the highest number of drugs in our study had eight while similar studies had 17 and 25 drugs prescribed. ${ }^{35,36}$ This significant difference in the number of prescribed drugs for patients in our study when compared to developed countries (eg, USA) could be attributed to a functional health insurance policy for the elderly which may give more access to medications. Another point to consider is the setting of this study; it was done among elderly patients living in predominantly rural areas in southwest Nigeria with a lifestyle and eating habits that differ from that of city dwellers. This might be responsible for the reduced number of comorbidities and, in effect, the number of drugs prescribed. The breakdown of the prescriptions showed that cardiovascular drugs, in particular antihypertensives, accounted for $30.6 \%$ of all prescriptions. In a study by Zaveri et al in India, 40.3\% of the prescribed drugs were antihypertensives. ${ }^{34}$ Calcium channel blockers $(10.5 \%)$ and diuretics $(10.4 \%)$ were the most prescribed antihypertensives among these patients, a finding consistent with another Nigerian study on drug use in hypertension. ${ }^{37}$ At variance with our findings are the results from a study in India, in which the beta-blocker Atenolol was the most prescribed antihypertensive. ${ }^{34}$ Multivitamins were the second most prescribed drug group in our study, followed by analgesics. In a study by Shah et al, multivitamins and analgesics constituted $10.8 \%$ and $9.7 \%$ of prescriptions, respectively. ${ }^{30}$ Tramadol, an opiate analog, comprised $17.8 \%$ of all prescribed analgesics in this study, higher than the 7.6\% and 9\% found in an American and Swedish study, respectively. ${ }^{38,39}$ The reason for the choice of Tramadol among prescribers may be the fact that NSAIDs, especially the nonspecific ones, are associated with increased gastrointestinal adverse effects among the elderly. Apart from the reason given above, the pool of available analgesics is limited especially after the prohibition of dipyrone (metamizole) and the non- 
licensing of dextropropoxyphene containing compounds by the Nigerian drug regulatory authorities because of their adverse effects. ${ }^{40,41}$ It is not surprising that antimalarial agents accounted for about $6.5 \%$ of the drugs prescribed, since Nigeria is a malaria endemic country and most patients presenting to the hospital are treated for malaria. Acetylsalicylic acid $(75 \mathrm{mg})$ is widely used for primary prevention of the complications of cardiovascular disease, and its presence in the prescriptions of about $8.6 \%$ of our cohort is likely due to this fact. Prescribing by generic name was not encouraging in this study and much progress has not been made from findings from older Nigerian studies with generic drugs accounting for $49.3 \%, 49.5 \%$, and $42.7 \%$ of all prescriptions, respectively. $23,24,42$

In our cohort, $25.5 \%$ of the patients had at least one encounter with a PIM. This is in the same range as results from the USA (27.5\%), Ireland (25\%), and Iran (27.6\%), and higher than the 9.8\% and $2.2 \%$ found in Turkey and Croatia, respectively. ${ }^{711,13,32,43}$ The very low proportion of patients with PIMs in the Croatian study was made possible by the use of computerized systems in the pharmacy and highlights the importance of information technology in medication management. NSAIDs, antihistamines, and amitriptylline, $\alpha$-Methyldopa, and longacting benzodiazepines were the common PIMs in this study. In a similar study by Azoulay et al, antihistamines were the most common PIMs, followed by NSAIDs and benzodiazepines. ${ }^{32}$ A Dutch study showed that nitrofurantoin, benzodiazepines, and amitriptylline were the commonly encountered PIMs, while findings from Turkey identified the centrally-acting antihypertensive reserpine and anti-platelet dipyridamole. ${ }^{11}$

\section{Limitations}

One of the limitations of this study is the fact that it was carried out in a rural setting and this may affect how our findings can be extrapolated to the generality of elderly patients, especially those residing in urban centers. Regarding the assessment of PIMs, the limitations of the Beers criteria stated earlier in the paper remains valid. Since it was developed for the USA, some of the medications listed on it may not have the same adverse effects on different populations. Also since we applied only the explicit Beers criteria (independent of diagnosis) in screening this cohort of patients, the obtained prevalence in this study may be lower than if the second criterion (considering diagnosis) was also applied.

\section{Conclusion}

Polypharmacy and the prescription of PIMs constitute a major problem, especially when dealing with the elderly.
Particular attention needs to be paid to the training of prescribers regarding geriatric patients. There is also a need for the development of a context-sensitive national list of PIMs that will reflect the peculiarities of the particular population.

\section{Acknowledgments}

We are grateful to the staff of Medical Records and the General Outpatient Departments of Federal Medical Centre, Ido-Ekiti, Nigeria for their assistance.

\section{Disclosure}

The authors report no conflicts of interest in this work.

\section{References}

1. US Census Bureau. Age: 2000 - Census 2000 Brief. Washington: US Census Bureau; 2001. Available from: http://www.census.gov/ prod/2001pubs/c2kbr01-12.pdf. Accessed January 8, 2012.

2. Sloan RW. Principles of drug therapy in geriatric patients. Am Fam Physician. 1992;45(6):2709-2718.

3. Chan DC, Hao YT, Wu SC. Characteristics of outpatient prescriptions for frail Taiwanese elders with long-term care needs. Pharmacoepidemiol Drug Saf. 2009;18(4):327-334.

4. Corona-Rojo JA, Altagracia-Martínez M, Kravzov-Jinich J, Vázquez-Cervantes L, Pérez-Montoya E, Rubio-Poo C. Potential prescription patterns and errors in elderly adult patients attending public primary health care centers in Mexico City. Clin Interv Aging. 2009;4:343-350.

5. Gallagher P, Barry P, O'Mahony D. Inappropriate prescribing in the elderly. J Clin Pharm Ther. 2007;32(2):113-121.

6. Jano E, Aparasu RR. Healthcare outcomes associated with beers' criteria: a systematic review. Ann Pharmacother. 2007;41(3):438-447.

7. Vlahović-Palcevski V, Bergman U. Quality of prescribing for the elderly in Croatia-computerized pharmacy data can be used to screen for potentially inappropriate prescribing. Eur J Clin Pharmacol. 2004;60(3): 217-220.

8. Beers MH. Explicit criteria for determining potentially inappropriate medication use by the elderly. An update. Arch Intern Med. 1997; 157(14):1531-1536.

9. Fick DM, Cooper JW, Wade WE, Waller JL, Maclean JR, Beers MH. Updating the Beers criteria for potentially inappropriate medication use in older adults: results of a US consensus panel of experts. Arch Intern Med. 2003;163(22):2716-2724.

10. American Geriatrics Society 2012 Beers Criteria Update Expert Panel. American Geriatrics Society updated Beers Criteria for potentially inappropriate medication use in older adults. $\mathrm{J}$ Am Geriatr Soc. 2012;60(4):616-631.

11. Ay P, Akici A, Harmanc H. Drug utilization and potentially inappropriate drug use in elderly residents of a community in Istanbul, Turkey. Int J Clin Pharmacol Ther. 2005;43(4):195-202.

12. Egger SS, Bachmann A, Hubmann N, Schlienger RG, Krähenbühl S. Prevalence of potentially inappropriate medication use in elderly patients: comparison between general medical and geriatric wards. Drugs Aging. 2006;23(10):823-837.

13. Gallagher P, O'Mahony D. STOPP (Screening Tool of Older Persons' potentially inappropriate Prescriptions): application to acutely ill elderly patients and comparison with Beers' criteria. Age Ageing 2008;37(6):673-679.

14. Maio V, Del Canale S, Abouzaid S; GAP Investigators. Using explicit criteria to evaluate the quality of prescribing in elderly Italian outpatients: a cohort study. J Clin Pharm Ther. 2010;35(2):219-229. 
15. de Oliveira Martins S, Soares MA, Foppe van Mil JW, Cabrita J. Inappropriate drug use by Portuguese elderly outpatients - effect of the Beers criteria update. Pharm World Sci. 2006;28(5):296-301.

16. Zhan C, Sangl J, Bierman AS, et al. Potentially inappropriate medication use in the community-dwelling elderly: findings from the 1996 Medical Expenditure Panel Survey. JAMA. 2001;286(22):2823-2829.

17. Steinman MA, Landefeld CS, Rosenthal GE, Berthenthal D, Sen S, Kaboli PJ. Polypharmacy and prescribing quality in older people. $J \mathrm{Am}$ Geriatr Soc. 2006;54(10):1516-1523.

18. Liu GG, Christensen DB. The continuing challenge of inappropriate prescribing in the elderly: an update of the evidence. JAm Pharm Assoc (Wash). 2002;42(6):847-857.

19. Harugeri A, Joseph J, Parthasarathi G, Ramesh M, Guido S. Potentially inappropriate medication use in elderly patients: a study of prevalence and predictors in two teaching hospitals. J Postgrad Med. 2010;56(3): 186-191.

20. Saab YB, Hachem A, Sinno S, El-Moalem H. Inappropriate medication use in elderly lebanese outpatients: prevalence and risk factors. Drugs Aging. 2006;23(9):743-752.

21. Lai HY, Hwang SJ, Chen YC, Chen TJ, Lin MH, Chen LK. Prevalence of the prescribing of potentially inappropriate medications at ambulatory care visits by elderly patients covered by the Taiwanese National Health Insurance program. Clin Ther. 2009;31(8):1859-1870.

22. Gallagher P, Ryan C, Byrne S, Kennedy J, O’Mahony D. STOPP (Screening Tool of Older Person's Prescriptions) and START (Screening Tool to Alert doctors to Right Treatment). Consensus validation. Int J Clin Pharmacol Ther. 2008;46(2):72-83.

23. Chang CB, Yang SY, Lai HY, et al. Using published criteria to develop a list of potentially inappropriate medications for elderly patients in Taiwan. Pharmacoepidemiol Drug Saf. 2012;21(12):1269-1279.

24. Adebayo ET, Hussain NA. Pattern of prescription drug use in Nigerian army hospitals. Ann Afr Med. 2010;9(3):152-158.

25. Enwere OO, Falade CO, Salako BL. Drug prescribing pattern at the medical outpatient clinic of a tertiary hospital in southwestern Nigeria. Pharmacoepidemiol Drug Saf. 2007;16(11):1244-1249.

26. Amanor-Boadu D. Pattern of drug use in geriatric patients undergoing surgery under general anaesthesia. Afr J Med Med Sci. 2002;31(1): 49-51.

27. Gavilán Moral E, Morales Suárez-Varela MT, Hoyos Esteban JA, Pérez Suanes AM. Inappropriate multiple medication and prescribing of drugs immobile elderly patients living in the community. Aten Primaria. 2006;38(9):476-480.

28. World Health Organization. World Health Statistics 2007. Geneva: World Health Organization; 2007. Available from: http://www.who. int/whosis/whostat2007.pdf. Accessed December 20, 2012.

29. CIA - The World Factbook [webpage on the Internet]. Nigeria: People and Society Washington, DC: Central Intelligence Agency; 2012 [updated January 7, 2013]. Available from: http://www.cia. gov/library/publications/the-world-factbook/geos/ni.html. Accessed December 20, 2012.

30. Shah RB, Gajjar BM, Desai SV. Drug utilization pattern among geriatric patients assessed with the anatomical therapeutic chemical classification/defined daily dose system in a rural tertiary care hospital. Int J Nutr Pharmacol Neurol Dis. 2012;2(3):258-265.
31. Central Statistics Office. Situation Analysis of the Elderly in India. New Dehli: Ministry of Statistics and Programme Implementation; 2011. Available from: http://mospi.nic.in/mospi_new/upload/elderly_ in_india.pdf. Accessed January 8, 2013.

32. Azoulay L, Zargarzadeh A, Salahshouri Z, Oraichi D, Bérard A. Inappropriate medication prescribing in community-dwelling elderly people living in Iran. Eur J Clin Pharmacol. 2005;61(12):913-919.

33. Shenoy S. Evaluation of the drug prescribing pattern in elderly patients in tertiary care hospital. Indian J Pharmacol. 2006;38(S):90.

34. Zaveri HG, Mansuri SM, Patel VJ. Use of potentially inappropriate medicines in elderly: A prospective study in medicine out-patient department of a tertiary care teaching hospital. Indian J Pharmacol. 2010;42(2):95-98.

35. Guaraldo L, Cano FG, Damasceno GS, Rozenfeld S. Inappropriate medication use among the elderly: a systematic review of administrative databases. BMC Geriatr. 2011;11:79.

36. Rajska-Neumann A, Wieczorowska-Tobis K. Polypharmacy and potential inappropriateness of pharmaco-logical treatment among community-dwelling elderly patients. Arch Gerontol Geriatr. 2007; 44 Suppl 1:303-309.

37. Olanrewaju TO, Aderibigbe A, Busari OA, Sanya EO. Antihypertensive drug utilization and conformity to guidelines in a sub-Saharan African hypertensive population. Int J Clin Pharmacol Ther. 2010;48(1): 68-75.

38. Cramer GW, Galer BS, Mendelson MA, Thompson GD. A drug use evaluation of selected opioid and nonopioid analgesics in the nursing facility setting. J Am Geriatr Soc. 2000;48(4):398-404.

39. Brattwall M, Turan I, Jakobsson J. Musculoskeletal pain: prescription of NSAID and weak opioid by primary health care physicians in Sweden 2004-2008 - a retrospective patient record review. J Pain Res. 2010;3: 131-135.

40. Public Alert On Safety Of Drugs Marketed/Manufactured In Nigeria And Other Countries [webpage on the Internet]. Abuja: National Agency for Food and Drug Administration and Control; 2011. Available from: http://www.nafdac.gov.ng/index.php/consumers/ recalls-alerts/recalls-a-safety-alerts/148-public-alert-on-safety-ofdrugs-marketedmanufactured-in-nigeria-and-other-countries. Accessed September 11, 2012.

41. Pharmacovigilance/FDIC Newsletter Vol 3 No 3, 2009. Abuja: National Agency for Food and Drug Administration and Control; 2009. Available from: http://www.nafdac.gov.ng/index.php/consumers/newsletters/ cat_view/45-pharmacovigilance-fdic-newsletter?limit=5\&limitstart= 0\&order=date\&dir=ASC. Accessed January 8, 2013.

42. Tamuno I, Fadare JO. Drug prescription pattern in a Nigerian tertiary hospital. Trop J Pharm Res. 2012;11(1):146-152.

43. Page RL 2nd, Ruscin JM. The risk of adverse drug events and hospital-related morbidity and mortality among older adults with potentially inappropriate medication use. Am J Geriatr Pharmacother. 2006;4(4):297-305.
Therapeutics and Clinical Risk Management

\section{Publish your work in this journal}

Therapeutics and Clinical Risk Management is an international, peerreviewed journal of clinical therapeutics and risk management, focusing on concise rapid reporting of clinical studies in all therapeutic areas, outcomes, safety, and programs for the effective, safe, and sustained use of medicines. This journal is indexed on PubMed Central, CAS,

\section{Dovepress}

EMBase, Scopus and the Elsevier Bibliographic databases. The manuscript management system is completely online and includes a very quick and fair peer-review system, which is all easy to use. Visit http://www.dovepress.com/testimonials.php to read real quotes from published authors. 